\section{Separation of Flavin and Phosphorylated Flavin}

Greene and Black ${ }^{1}$ have found that phenol, the cresols, aniline and benzyl-alcohol are suitable for the extraction of free flavin from water.

Using a solution of phosphorylated flavin (purified liver extract), I found that phenol also rapidly took up phosphorylated flavin from water.

It appeared, however, that practically no phosphorylated flavin was extracted by benzyl-alcohol when a solution of phosphorylated flavin in water was shaken with an equal volume of benzyl-alcohol $(p \mathrm{H}$ values from 5 to 7.4 and salt concentrations from 0.5 to 4.5 per cent $\mathrm{NaCl}$ ). Under these conditions one benzyl-alcohol extraction removed 76-79 per cent of free flavin from water. Other aromatic alcohols (phenylethanol, phenylpropanol and phenylethylmethylethylcarbinol also permitted a separation.

Details and applications by these methods of separation (for example, urinary excretion) will be published elsewhere.

\section{Laboratory of Hygiene, \\ University, Utrecht. Feb. 7. \\ 1J. Amer. Chem. Soc., 59, 1820 (1937).}

a known quantity of $\gamma$-rays from radium, we measured the intensity of neutrons, and the result showed that, at $250 \mathrm{kv}$. and $20 \mu \mathrm{A}$., the ionization at $3.5 \mathrm{~cm}$. from the source was equal to $1.3 \mathrm{r} /$ hour. The following observations were made by irradiating young rats of about $20 \mathrm{gm}$. body weight with 10-30 r of D.D.neutrons.

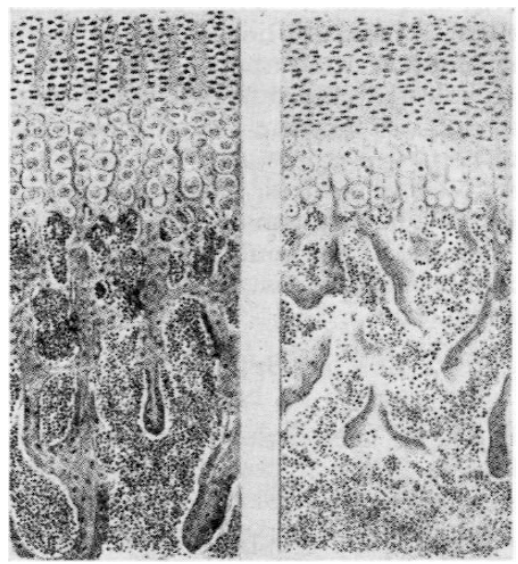

Fig. 2.

BONE AND BONE MARROW BEFORE (LEFT) AND AFTER (RIGHT) IRRADIATION.

Tur biologicel effects of neutrons produced by cyclotron have been reported by Lawrence and others. However, neutrons generated by a cyclotron, using beryllium targets, are accompanied by a great deal of $\gamma$-radiation, and the effect cannot be attributed entirely to neutrons. The purest neutrons ever known are D-D-neutrons, which are produced by bombarding 'heavy' ice $\left(\mathrm{D}_{2} \mathrm{O}\right)$ with deuterons accelerated by high voltage, that is, by the reaction of

$$
{ }_{1} \mathrm{D}^{2}+{ }_{1} \mathrm{D}^{2} \rightarrow{ }_{2} \mathrm{He}^{3}+{ }_{0} n^{1} \text {. }
$$

Since June 1937, through the kindness of the Nishikawa Laboratory of the Institute of Physical and Chemical Research, Tokyo, I have been examining

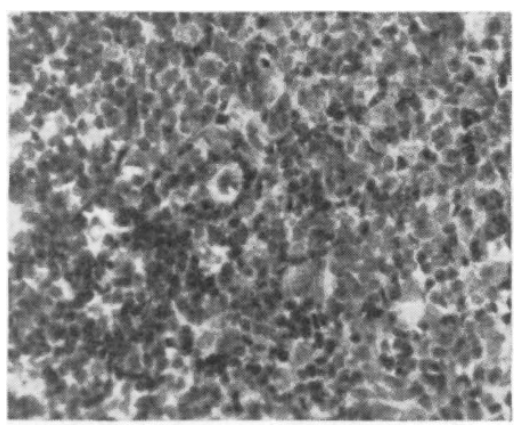

Fig. 1.

IRRADIATED THYMUS.

the biological effects on young rats of irradiating them with D.D-neutrons. As the maximum range of recoil protons generated by neutrons is great, we have made a special ionization chamber with alum. inium walls $2 \mathrm{~mm}$. thick, lined with a $0.2 \mathrm{~mm}$. layer of paraffin, and filled with methane gas, in order to measure the total ionization. By comparison with
The rats, irradiated with $30 \mathrm{r}$, did not increase in weight, and died in 5-10 days. With $26 \mathrm{r}$, rats showed no increase in weight for more than two weeks. About one half the amount of neutrons abovementioned allowed the rats to increase slightly in weight after a week, but they were still very poor in growth, even after four weeks. After irradiation with $12 \mathrm{r}$, the total leucocytes decreased to about one half, that is, $3,600-4,800$. This state continued with or without further irradiation. The most con. spicuous was the decrease of lymphocytes, which decreased from $70-80$ per cent to $20-40$ per cent, and their absolute number was so low as 1000 or less after two weeks. Neutrophil leucocytes, on the other hand, increased from 12-20 per cent to $40-77$ per cent, and their absolute number also increased. Monocytes increased for a time, but afterward decreased, and eosinophil leucocytes gradually decreased and finally disappeared. Red cells and hæmoglobin gradually decreased, nucleated red cells appearing in the circulating blood in many cases.

At necropsy, anæmia of every organ was marked. Spleen, testis, ovary, thymus, bone, etc., were especially decreased considerably in size. Microscopically, the lymph follicles of the spleen were found to be most quickly affected, where destruction or decrease of lymphoid cells could be seen. Following this, the degeneration of megacaryocytes in pulp came about. Two weeks after exposure to 26-30 r, we found practically no lymphoid cells in the lymph follicles, reticulum cells remained withered in thread. like form, and infiltration of polymorphonuclear leucocytes appeared. Megacaryocytes in pulp having almost gone, many small round myeloid cells with positive oxidase reaction appeared. There were also hæmosiderosis and erythrophagia. Four weeks after, many megacaryocytes appeared, also many myeloid cells, showing bloomy myeloid metaplasia, but the regeneration of lymph follicles was still unsatisfactory. 